Research Article

\title{
Layout Method of Multiseismic Detectors for Shallow Underground Excavation Applications
}

\author{
Dong-ze Qin (D) and Jin-Shi Zhang \\ School of Mechatronic Engineering, North University of China, Taiyuan 030051, China \\ Correspondence should be addressed to Dong-ze Qin; apo1981@126.com
}

Received 8 February 2020; Revised 13 March 2020; Accepted 22 April 2021; Published 7 May 2021

Academic Editor: Jesús Lozano

Copyright () 2021 Dong-ze Qin and Jin-Shi Zhang. This is an open access article distributed under the Creative Commons Attribution License, which permits unrestricted use, distribution, and reproduction in any medium, provided the original work is properly cited.

In this study, we propose effective monitoring equipment intended for monitoring the underground tunnel of illegal excavation (such as theft, jailbreak, and smuggling). It mainly detects the microseismic information produced by underground excavation in a short distance to detect the status of underground excavation. Based on the arrival time difference principle, the positioning mathematical models of the 5-1-1 layout method, 4-3 layout method, and 7-0-0 layout method are established, respectively. In the research process, the measurement and the placement error caused by the installation of a seismic detector are joined into the detectors. Simulation results show that the relative error and its average value are obtained when mining outside the monitoring area. The experiment results demonstrate that, first, the depth positioning error is positively affected by the number of seismic detectors. Then, the relative error of plane positioning can be reduced when the installation distance among detectors is increased. Finally, the main causes of location error include time measurement error, propagation velocity difference caused by terrain, and the performance of detector hardware. The array of a ground motion detector has a weak influence on it. These emerging trends will have profound impacts on application of an underground excavation system.

\section{Introduction}

1.1. Background. The underground excavation monitoring system is an effective monitoring device used to monitor crimes such as theft, jailbreak, and smuggling through shallow underground excavation. The system locates the excavation location mainly through the microseismic information sensed by multiple-seismic detectors.

1.2. Research Status. Based on the sensor's monitoring of seismic signals, the spatial coordinates and seismic moments of the source are determined. It is one of the main contents of seismic positioning research. Regarding the seismic source positioning method, the predecessor has done a lot of research and put forward a lot of positioning methods, such as Geiger and various improvement methods, joint correction method for the source location and station, relative positioning method, station-pair time difference method, EHB method, and double residual method. The development of seismic source location research has been greatly promoted.
These methods can be divided into two categories depending on the parameters involved in solving: one is the method for solving the timing of shocks and the location of microseismic sources after knowing the velocity models, referred to as the classic method [1-6], and the other is the method for solving the seismic source location, the shock time, and the velocity model together, referred to as the joint method. The former is the most widely used in the seismic field and mining engineering, and the uncertainty of the velocity model is the biggest deficiency of the method. Although many studies have been done on the velocity model before it, it is still the biggest factor affecting the stability and accuracy of the positioning algorithm. The latter solves the problem of the uncertain velocity model and greatly improves the accuracy of microseismic source positioning. But the parameters of microseismic source location, shock time, and media velocity are not independent of each other; the solution is not unique, which brings difficulties to the selection of parameters [7-18].

However, the underground excavation monitoring is a new engineering application, and the relevant research 
TABLE 1: Comparison of several common locating methods.

\begin{tabular}{|c|c|c|c|c|}
\hline Locating method & Advantage & Disadvantage & Accuracy & Time-consuming \\
\hline TOA & $\begin{array}{l}\text { Simple technique and } \\
\text { algorithm }\end{array}$ & $\begin{array}{c}\text { Moving targets and nodes always } \\
\text { are precisely synchronized. But it is } \\
\text { susceptible to multipath propagation } \\
\text { and noise }\end{array}$ & Relatively high & Long \\
\hline TDOA & $\begin{array}{c}\text { Relatively simple } \\
\text { technique and algorithm }\end{array}$ & $\begin{array}{l}\text { Accuracy is greatly affected by the } \\
\text { environment, and it requires accurate } \\
\text { synchronization of node clocks }\end{array}$ & Relatively high & Relatively long \\
\hline DOA & $\begin{array}{c}\text { Relatively simple } \\
\text { technique and algorithm }\end{array}$ & $\begin{array}{c}\text { Easily affected by the environment } \\
\text { and low accuracy }\end{array}$ & Relatively low & Short \\
\hline RSSI & $\begin{array}{l}\text { Relatively simple } \\
\text { technology, low cost, } \\
\text { high precision for short } \\
\text { range }\end{array}$ & $\begin{array}{l}\text { It is easily affected by the environment, } \\
\text { the accuracy } \\
\text { is poor for outdoor long-range locating, } \\
\text { and it is easily susceptible to } \\
\text { multipath propagation }\end{array}$ & $\begin{array}{l}\text { High (for short range), low } \\
\text { (for long range) }\end{array}$ & l \\
\hline
\end{tabular}

cannot be used for reference. It is also different from the traditional location of an underground seismic source and ground sensor network.

The instrument used in traditional underground source location has high price and good performance. It can distinguish $S$-wave and $P$-wave in seismic wave and is easy to identify signal. The hardware performance is quite different from that of the system proposed in this paper.

Because the monitoring distance of underground excavation monitoring is close and the monitoring depth is shallow, the monitored signal $S$-wave, $P$-wave, and Rayleigh wave are mixed together. The performance of traditional equipment is common, which makes it difficult to judge the waveform accurately, which may lead to the low accuracy of velocity measurement.

Due to the lack of relevant research, it is not clear whether the traditional source location method is applicable or not and the influence of the layout method of a ground motion detector on the positioning accuracy.

In view of the above problems, this paper combines with the engineering practice of underground excavation application to carry out research.

\subsection{Contribution}

(1) Based on the principle of TDOA, this paper puts forward three layout methods applied to an underground excavation monitoring system and deduces the relevant mathematical model

(2) In this paper, the experiments of common ground motion detectors show that the $S$-wave, $P$-wave, and Rayleigh wave are mixed together, and it is difficult to judge the first arrival wave accurately. Moreover, when the excavation points are different, the geological difference and the calculation dispersion of seismic wave velocity will lead to large positioning error, and the layout of array has little impact on the positioning error. The simulation results also support this argument. Therefore, the application value of the location method based on the TDOA principle in the underground excavation monitoring system is limited

\section{The Locating Methods}

Locating methods are mainly divided into active locating and passive locating. Active locating is a method that uses radar, laser, and other active devices to locate the target. Passive locating is based on receiving and processing the radiation source's signals generated by the target and extracting information such as the distance, azimuth, and tracking of the target. Passive locating overcomes the disadvantages of large power consumption and the large volume of active locating. In this paper, multiseismic detectors are used to locate underground excavation, which is a passive location method.

At present, the methods of the passive locating algorithms are mainly based on Time of Arrival (TOA), based on TDOA, based on the Direction of Arrival (DOA), and based on Received Signal Strength Indication (RSSI). Table 1 is the compared results of common passive locating methods. The TDOA is a widely used method because of its simple algorithm and no precise synchronization between the target and the node [18-24].

\section{Math Modeling of Layout Methods}

3.1. The Mathematical Modeling of Locating. The key point of the TDOA locating method is the estimation of the arrival time difference. Different from the traditional planar TDOA locating algorithm, locating needs to calculate coordinate positions of $x, y, z$, so at least four seismic detectors are needed to form the equations. The location of the receiving seismic detector is $S_{1}\left(x_{1}, y_{1}, z_{1}\right), S_{2}\left(x_{2}, y_{2}, z_{2}\right), S_{3}\left(x_{3}, y_{3}, z_{3}\right)$, and $S_{4}\left(x_{4}, y_{4}, z_{4}\right)$, respectively. The location of the measured object is $P(x, y, z)$. And the distance between the measured object and four seismic detectors are $d_{1}, d_{2}, d_{3}, d_{4}$, respectively. According to the distance calculation equation, a nonlinear equation group can be obtained. 


$$
\left\{\begin{array}{l}
\left(x-x_{1}\right)^{2}+\left(y-y_{1}\right)^{2}+\left(z-z_{1}\right)^{2}=d_{1}^{2}, \\
\left(x-x_{2}\right)^{2}+\left(y-y_{2}\right)^{2}+\left(z-z_{2}\right)^{2}=d_{2}^{2}, \\
\left(x-x_{3}\right)^{2}+\left(y-y_{3}\right)^{2}+\left(z-z_{3}\right)^{2}=d_{3}^{2}, \\
\left(x-x_{4}\right)^{2}+\left(y-y_{4}\right)^{2}+\left(z-z_{4}\right)^{2}=d_{4}^{2} .
\end{array}\right.
$$

The coordinates of the measured excavation location $P$ can be obtained.

$$
\begin{aligned}
{\left[\begin{array}{l}
x \\
y \\
z
\end{array}\right]=} & {\left[\begin{array}{lll}
2\left(x_{1}-x_{4}\right) & 2\left(y_{1}-y_{4}\right) & 2\left(z 1-z_{4}\right) \\
2\left(x_{2}-x_{4}\right) & 2\left(y_{2}-y_{4}\right) & 2\left(z_{2}-z_{4}\right) \\
2\left(x_{3}-x_{4}\right) & 2\left(y_{3}-y_{4}\right) & 2\left(z_{3}-z_{4}\right)
\end{array}\right]^{-1} } \\
& +\left[\begin{array}{l}
d_{4}^{2}-d_{1}^{2}+x_{1}^{2}-x_{4}^{2}+y_{1}^{2}-y_{4}^{2}+z_{1}^{2}-z_{4}^{2} \\
d_{4}^{2}-d_{2}^{2}+x_{2}^{2}-x_{4}^{2}+y_{2}^{2}-y_{4}^{2}+z_{2}^{2}-z_{4}^{2} \\
d_{4}^{2}-d_{3}^{2}+x_{3}^{2}-x_{4}^{2}+y_{3}^{2}-y_{4}^{2}+z_{3}^{2}-z_{4}^{2}
\end{array}\right] .
\end{aligned}
$$

When the number of seismic detectors increases, the equation obtained by the distance calculation equation increases correspondingly. In this case, we use the maximum likelihood method to calculate the position coordinates of the measured target. The position coordinates of $n$ seismic detectors are, respectively, $\left(x_{1}, y_{1}, z_{1}\right),\left(x_{2}, y_{2}, z_{2}\right),\left(x_{3}, y_{3}, z_{3}\right)$ ,$\cdots\left(x_{n}, y_{n}, z_{n}\right)$. Supposing that the measured excavation location coordinate is $P(x, y, z)$, we can get

$$
\left\{\begin{array}{l}
\left(x-x_{1}\right)^{2}+\left(y-y_{1}\right)^{2}+\left(z-z_{1}\right)^{2}=d_{1}^{2}, \\
\left(x-x_{2}\right)^{2}+\left(y-y_{2}\right)^{2}+\left(z-z_{2}\right)^{2}=d_{2}^{2}\left(x-x_{2}\right)^{2}+\left(y-y_{2}\right)^{2}+\left(z-z_{2}\right)^{2}=d_{2}^{2}, \\
\vdots \\
\left(x-x_{n}\right)^{2}+\left(y-y_{n}\right)^{2}+\left(z-z_{n}\right)^{2}=d_{n}^{2} .
\end{array}\right.
$$

The distance between the measured target's location and each seismic is unknown, and it can be converted into the product of velocity and time according to the distance equation.

$$
\left\{\begin{array}{l}
d_{1}=v\left(t_{1}-t\right) \\
d_{2}=v\left(t_{2}-t\right) \\
\vdots \\
d_{n}=v\left(t_{n}-t\right)
\end{array}\right.
$$

where $v$ is the propagation velocity of the seismic waves, $t_{n}$ is the moment for each seismic detector receiving the seismic wave signal, and $t$ is the moment for excavation signal beginning.

$$
\left\{\begin{array}{l}
2 x\left(x_{1}-x_{n}\right)+2 y\left(y_{1}-y_{n}\right)+2 z\left(z_{1}-z_{n}\right)+2 t\left(t_{n}-t_{1}\right) v^{2}=v^{2}\left(t_{n}^{2}-t_{1}^{2}\right)+x_{1}^{2}-x_{n}^{2}+y_{1}^{2}-y_{n}^{2}+z_{1}^{2}-z_{n}^{2} \\
2 x\left(x_{2}-x_{n}\right)+2 y\left(y_{2}-y_{n}\right)+2 z\left(z_{2}-z_{n}\right)+2 t\left(t_{n}-t_{2}\right) v^{2}=v^{2}\left(t_{n}^{2}-t_{2}^{2}\right)+x_{2}^{2}-x_{n}^{2}+y_{2}^{2}-y_{n}^{2}+z_{2}^{2}-z_{n}^{2} \\
\vdots \\
2 x\left(x_{n-1}-x_{n}\right)+2 y\left(y_{n-1}-y_{n}\right)+2 z\left(z_{n-1}-z_{n}\right)+2 t\left(t_{n}-t_{n-1}\right) v^{2}=v^{2}\left(t_{n}^{2}-t_{n-1}^{2}\right)+x_{n-1}^{2}-x_{n}^{2}+y_{n-1}^{2}-y_{n}^{2}+z_{n-1}^{2}-z_{n}^{2}
\end{array}\right.
$$

This is a form of $A X=b$, where

$$
\begin{aligned}
& \mathrm{A}=\left[\begin{array}{cccc}
2\left(x_{1}-x_{n}\right) & 2\left(y_{1}-y_{n}\right) & 2\left(z_{1}-z_{n}\right) & 2\left(t_{n}-t_{1}\right) v^{2} \\
2\left(x_{2}-x_{n}\right) & 2\left(y_{2}-y_{n}\right) & 2\left(z_{2}-z_{n}\right) & 2\left(t_{n}-t_{2}\right) v^{2} \\
\vdots & & \\
2\left(x_{n-1}-x_{n}\right) & 2\left(y_{n-1}-y_{n}\right) & 2\left(z_{n-1}-z_{n}\right) & 2\left(t_{n}-t_{n-1}\right) v^{2}
\end{array}\right], \quad X=\left[\begin{array}{c}
x \\
y \\
z \\
t
\end{array}\right] \\
& b=\left[\begin{array}{c}
v^{2}\left(t_{n}^{2}-t_{1}^{2}\right)+x_{1}^{2}-x_{n}^{2}+y_{1}^{2}-y_{n}^{2}+z_{1}^{2}-z_{n}^{2} \\
v^{2}\left(t_{n}^{2}-t_{2}^{2}\right)+x_{2}^{2}-x_{n}^{2}+y_{2}^{2}-y_{n}^{2}+z_{2}^{2}-z_{n}^{2} v^{2}\left(t_{n}^{2}-t_{2}^{2}\right)+x_{2}^{2}-x_{n}^{2}+y_{2}^{2}-y_{n}^{2}+z_{2}^{2}-z_{n}^{2} \\
\vdots \\
v^{2}\left(t_{n}^{2}-t_{n-1}^{2}\right)+x_{n-1}^{2}-x_{n}^{2}+y_{n-1}^{2}-y_{n}^{2}+z_{n-1}^{2}-z_{n}^{2} v^{2}\left(t_{n}^{2}-t_{n-1}^{2}\right)+x_{n-1}^{2}-x_{n}^{2}+y_{n-1}^{2}-y_{n}^{2}+z_{n-1}^{2}-z_{n}^{2}
\end{array}\right] .
\end{aligned}
$$


The solution of the equation which is solved by the standard minimum mean square estimation method is $X^{\wedge}=\left(A^{T} A\right)^{-1}$ $A^{T} b$, and it can be used as the coordinate of the excavation location. Since the propagation velocity of seismic waves is unknown, the seismic waves' velocity generated by underground excavation needs to be estimated.

The estimation of the propagation velocity of seismic wave is calculated based on the distance-time equation, and the specific calculation method is as follows: to simplify the calculation, excavation action is performed at a certain point (within the detection range of the seismic detector) on the extended line of two seismic detectors, and then, the time difference is given by processing the information collected by two seismic detectors. Then, measure the distance between two seismic detectors. The propagation velocity of the seismic wave is estimated by

$$
v=\left|\frac{d_{12}}{t_{1}-t_{2}}\right|,
$$

where $d_{12}$ is the linear distance between two seismic detectors, $t_{1}$ is the time of the target detected by $S_{1}$, and $t_{2}$ is the time of the target detected by $S_{2}$.

For popularizing the more general calculation equation of seismic waves' propagation velocity, the excavation behavior of anywhere within the detection range of a seismic detector can be used as a signal source; then, the equation of the seismic waves' propagation velocity becomes

$$
v=\left|\frac{d_{1}-d_{2}}{t_{1}-t_{2}}\right|=\left|\frac{\Delta d_{12}}{\Delta t_{12}}\right|,
$$

where $\Delta t_{12}$ is the delay of two seismic detectors obtaining the target signal, $d_{1}$ is the distance between the target and the seismic detector $S_{1}, d_{2}$ is the distance between the target and the seismic detector $S_{2}$, and $\Delta d_{12}$ is the difference in distance between the target and the two seismic detectors.

For making the measured propagation velocity more comprehensively reflect the seismic wave propagation velocity characteristics of the entire detection area, it is necessary to repeat the calculation in different positions multiple times and get an average value.

3.2. The Mathematical Model of Layout Methods. In general, the more the seismic detectors, the higher the accuracy. However, in actual engineering applications, it is impossible to increase the number of seismic detectors unlimitedly due to the cost. For convenience, we build a submonitoring area using seven seismic detectors, respectively $S_{1} \sim S_{7}$.

3.2.1. The 5-1-1 Layout Method. As shown in Figure 1, the 51-1 layout method consists of 7 seismic detectors. We set the space Cartesian coordinate system with $S_{7}$ the origin of coordinates and list the coordinates of each sensor as follows ( $e, f, g$, and $h$ are constants). $r+e$ represents the

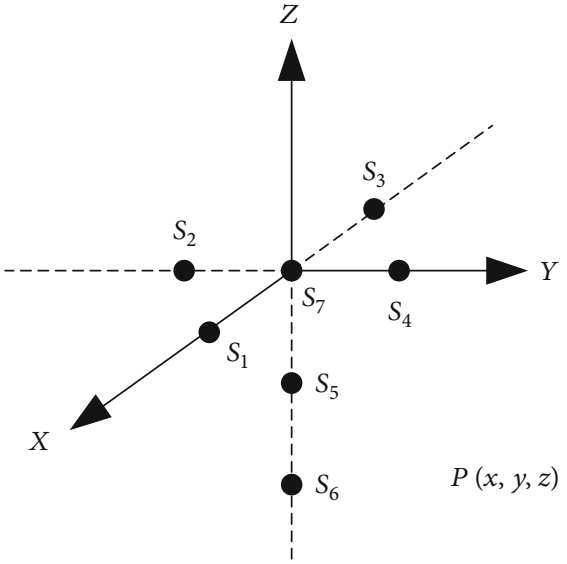

Figure 1: The 5-1-1 layout method.

coordinates of the $S_{5}$ seismic detector in the $X$ axial direction. $f$ represents the coordinates of the $S_{5}$ seismic detector in the $Z$ axial direction. $r+g$ represents the coordinates of the $S_{6}$ seismic detector in the $X$ axial direction. $h$ represents the coordinates of the $S_{6}$ seismic detector in the $Z$ axial direction.

$$
\begin{aligned}
& S_{1}(r, 0,0), \\
& S_{2}(0,-r, 0), \\
& S_{3}(-r, 0,0), \\
& S_{4}(0, r, 0), \\
& S_{5}(r+e, 0,-f), \\
& S_{6}(r+g, 0,-h), S_{7}(0,0,0) .
\end{aligned}
$$

The mathematical model is established by using the coordinates of seven seismic detectors.

$$
\begin{aligned}
& f 1: \sqrt{(\mathrm{x}-r)^{2}+y^{2}+z^{2}}=v\left(t_{1}-t\right), \\
& f 2: \sqrt{x^{2}+(y+r)^{2}+z^{2}}=v\left(t_{2}-t\right), \\
& f 3: \sqrt{(x+r)^{2}+y^{2}+z^{2}}=v\left(t_{3}-t\right), \\
& f 4: \sqrt{x^{2}+(y-r)^{2}+z^{2}}=v\left(t_{4}-t\right), \\
& f 5: \sqrt{(x-r-e)^{2}+y^{2}+(z+f)^{2}}=v\left(t_{5}-t\right), \\
& f 6: \sqrt{(x-r-g)^{2}+y^{2}+(z+h)^{2}}=v\left(t_{6}-t\right), \\
& f 7: \sqrt{x^{2}+y^{2}+z^{2}}=v\left(t_{7}-t\right) .
\end{aligned}
$$

3.2.2. The 4-3 Layout Method. As shown in Figure 2, the 43 layout method consists of 7 seismic detectors. We set the space Cartesian coordinate system with $S_{7}$ the origin of coordinates and list the coordinates of each sensor as follows $(i, j$, $k$, and $u$ are constants). $r+i$ represents the coordinates of the $S_{5}$ seismic detector in the $X$ axial direction. $j$ represents 


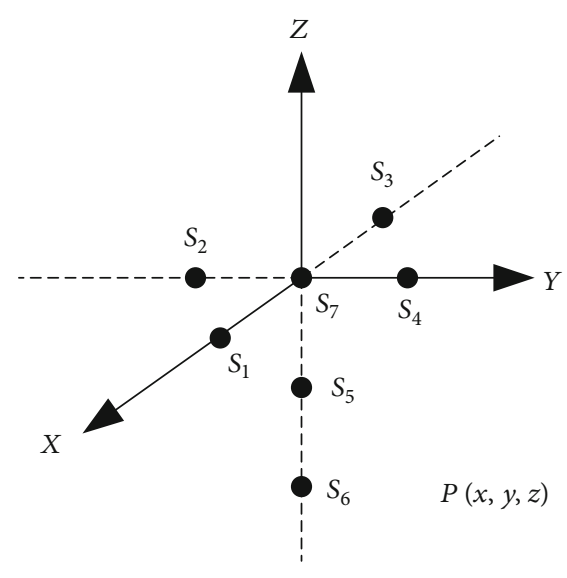

FIgURE 2: The 4-3 layout method.

the coordinates of the $S_{5}$ seismic detector in the $Y$ axial direction. $k$ represents the coordinates of the seismic detector in the $Z$ axial direction.

The mathematical model is established by using the coordinates of seven seismic detectors.

$$
\begin{gathered}
S_{1}(r, 0,0), \\
S_{2}(0,-r, 0), \\
S_{3}(-r, 0,0), \\
S_{4}(0, r, 0), \\
S_{5}(r+i,-j,-k), \\
S_{6}(r+u, 0,-k), \\
S_{7}(i+r, j,-k), \\
f 1: \sqrt{(x-r)^{2}+y^{2}+z^{2}}=v\left(t_{1}-t\right), \\
f 2: \sqrt{x^{2}+(y+r)^{2}+z^{2}}=v\left(t_{2}-t\right), \\
f 3: \sqrt{(x+r)^{2}+y^{2}+z^{2}}=v\left(t_{3}-t\right), \\
f 7: \sqrt{\mathrm{x}^{2}+(y-r)^{2}+z^{2}}=v\left(t_{4}-t\right), \\
f 6: \sqrt{(\mathrm{x}-r-u)^{2}+y^{2}+(z+k)^{2}}=v\left(t_{6}-t\right), \\
f 5)^{2}+(y-j)^{2}+(z+k)^{2}=v\left(t_{7}-t\right) . \\
f 5)^{2}+(z+k)^{2} \\
f 5\left(t_{5}-t\right),
\end{gathered}
$$

3.2.3. The 7-0-0 Layout Method. As shown in Figure 3, the 70-0 layout method consists of 7 seismic detectors. We set the space Cartesian coordinate system with $S_{7}$ the origin of coordinates and list the coordinates of each sensor as follows.

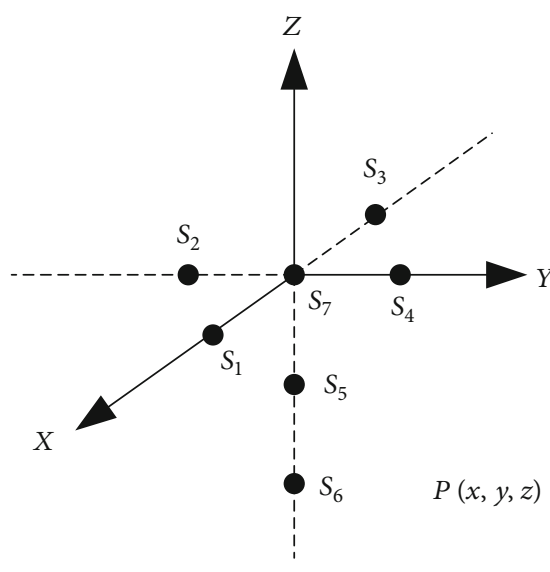

FIgURE 3: The 7-0-0 layout method.

$$
\begin{aligned}
& S_{1}(r, 0,0), \\
& S_{2}(0,-r, 0), \\
& S_{3}(-r,-r, 0), \\
& S_{4}(-r, 0,0), \\
& S_{5}(-r, r, 0), \\
& S_{6}(0, r, 0), \\
& S_{7}(0,0,0) .
\end{aligned}
$$

The mathematical model is established by using the coordinates of seven seismic detectors.

$$
\begin{aligned}
& f 1: \sqrt{(x-r)^{2}+(y)^{2}+z^{2}}=v\left(t_{1}-t\right), \\
& f 2: \sqrt{x^{2}+(y+r)^{2}+z^{2}}=v\left(t_{2}-t\right), \\
& f 3: \sqrt{(x+r)^{2}+(y+r)^{2}+z^{2}}=v\left(t_{3}-t\right), \\
& f 4: \sqrt{(\mathrm{x}+\mathrm{r})^{2}+y^{2}+z^{2}}=v\left(t_{4}-t\right), \\
& f 5: \sqrt{(x+r)^{2}+(y-r)^{2}+z^{2}}=v\left(t_{5}-t\right), \\
& f 6: \sqrt{\mathrm{x}^{2}+(y-r)^{2}+z^{2}}=v\left(t_{6}-t\right), \\
& f 7: \sqrt{\mathrm{x}^{2}+y^{2}+z^{2}}=v\left(t_{7}-t\right) .
\end{aligned}
$$

\section{Simulation and Experimental Analysis}

4.1. Simulation Results. Combined with the actual situation of the underground excavation monitoring system, the main factors that affect the locating accuracy are analyzed as follows: the measurement error of seismic detectors, the spacing of seismic detectors, the propagation velocity of seismic waves, the error of seismic detectors, and the position of mining's coordinate. Due to the limited detection range of 

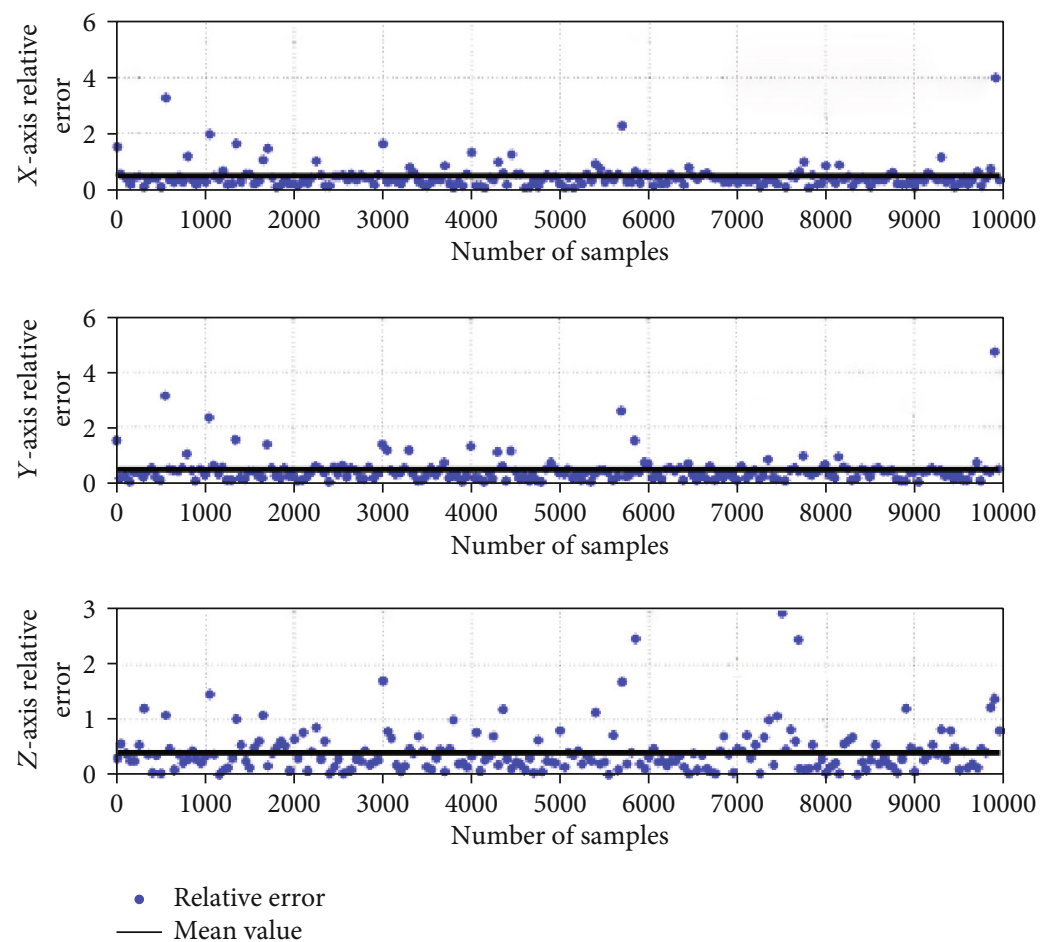

Figure 4: The simulation chart for the 5-1-1 layout method of excavation location P1, when $r=2 \mathrm{~m}$.
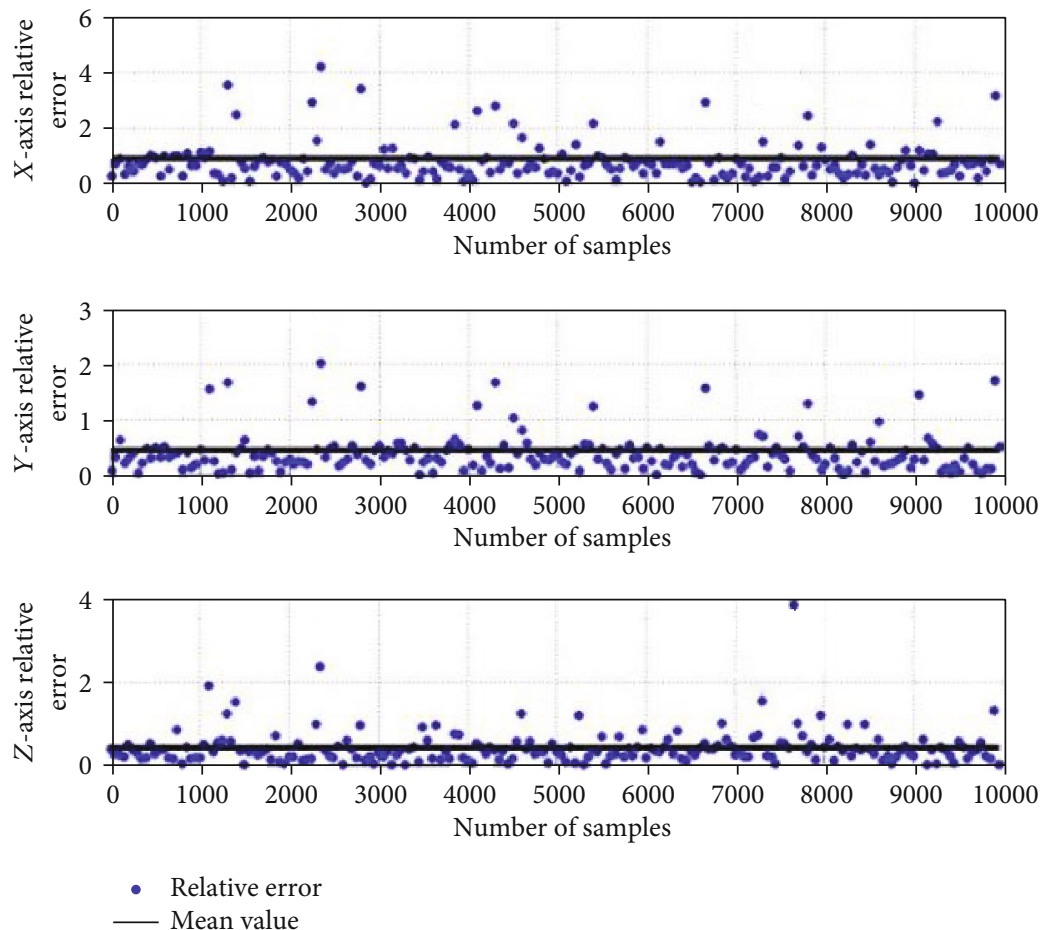

Figure 5: The simulation chart for the 5-1-1 layout method of excavation location P2, when $r=2 \mathrm{~m}$.

seismic detectors, combined with the actual working conditions, it is assumed that a submonitoring system consists of seven seismic detectors. Due to the difference of the time signals received by each seismic detector, the measurement error and the position error generated by the sensor placement are introduced into each seismic detector to calculate the relative error and the average of the relative errors of each axis during locating. It is assumed that the geological 

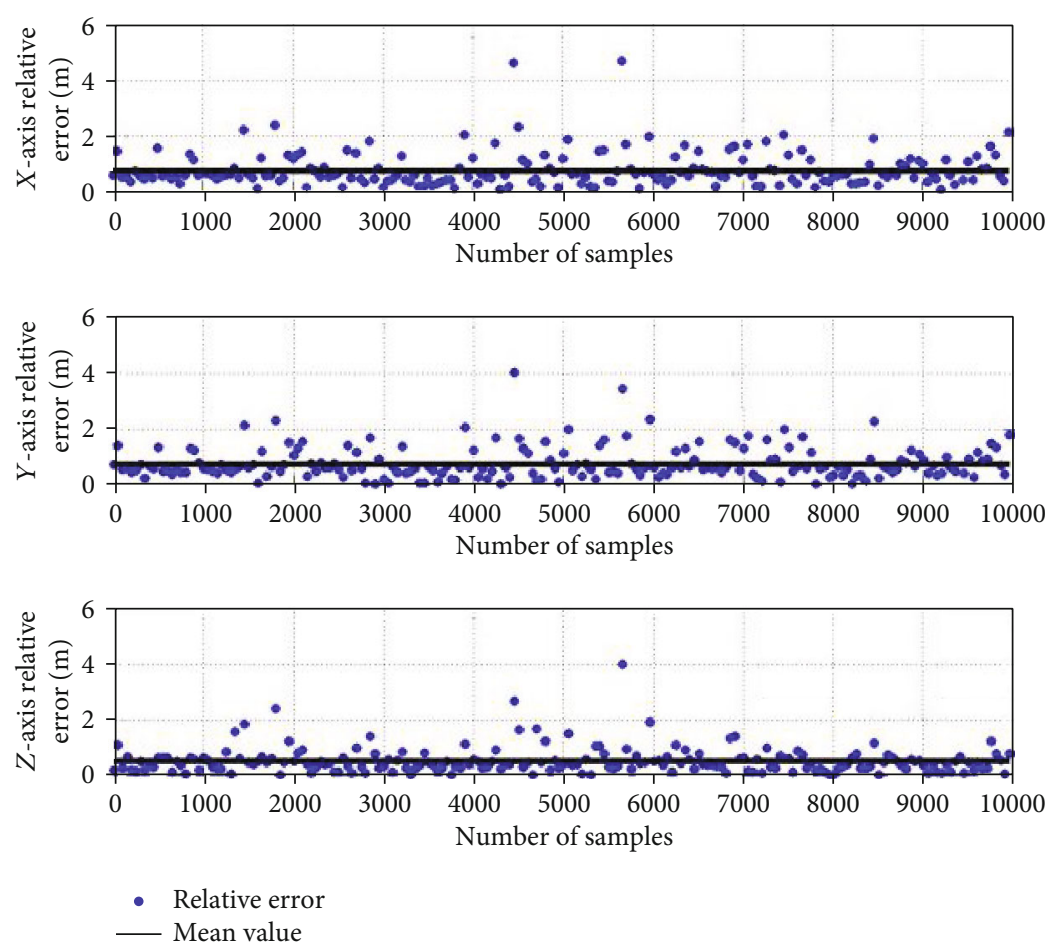

FIGURE 6: The simulation chart for the 5-1-1 layout method of excavation location P1, when $r=1.5 \mathrm{~m}$.
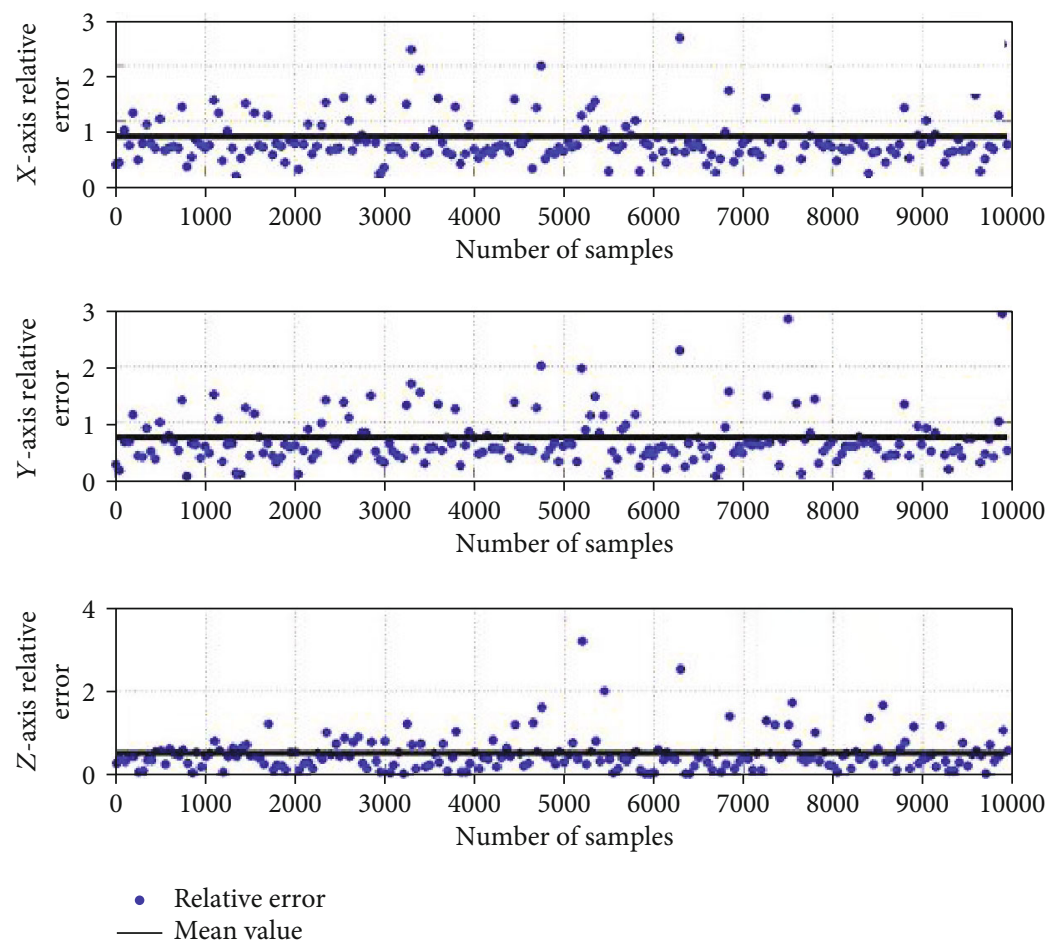

Figure 7: The simulation chart for the 5-1-1 layout method of excavation location P2, when $r=1.5 \mathrm{~m}$.

conditions are the same, taking the soil as an example. Because of the shallow excavation, assume that the underground excavation site is outside and that the seismic wave propagation velocity is constant and the velocity is $380 \mathrm{~m} / \mathrm{s}$.
4.1.1. The Simulation of the 5-1-1 Layout Method. In order to facilitate the test verification, combined with the performance of the experimental site and experimental equipment, the distance between the seismic detectors assumed in the 

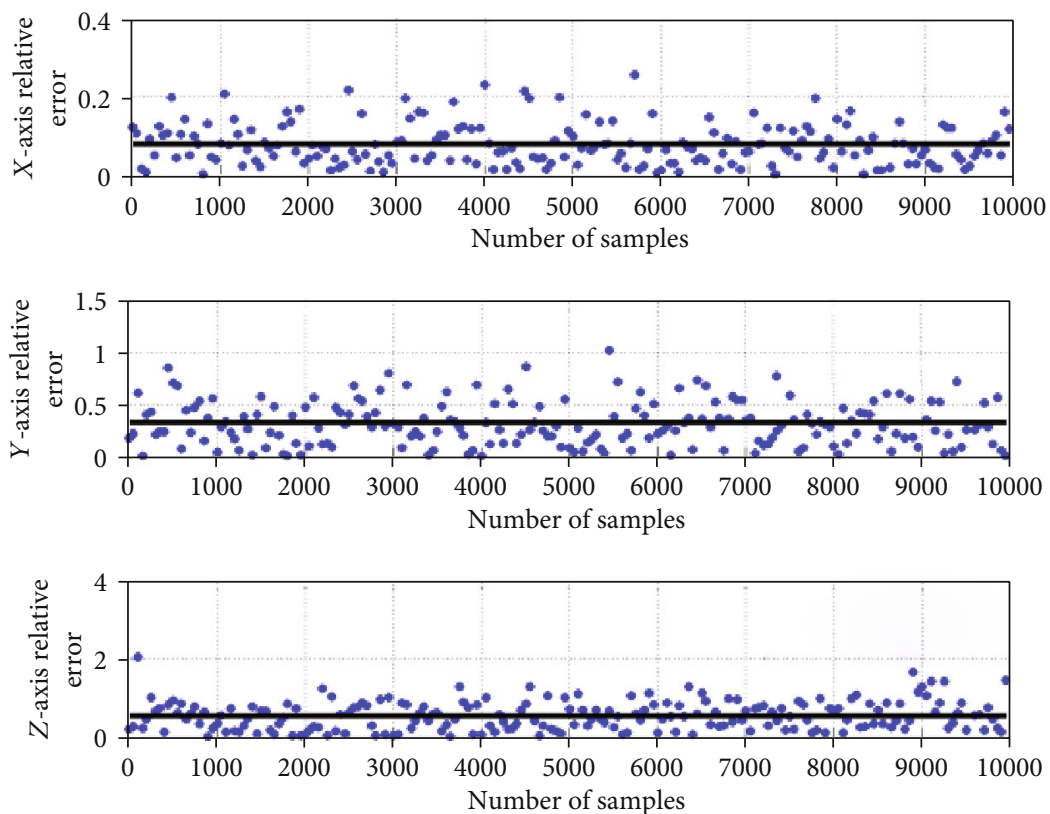

- Relative error

— Mean value

FIgURE 8: The simulation chart for the 4-3 layout method of excavation location P1, when $r=2 \mathrm{~m}$.
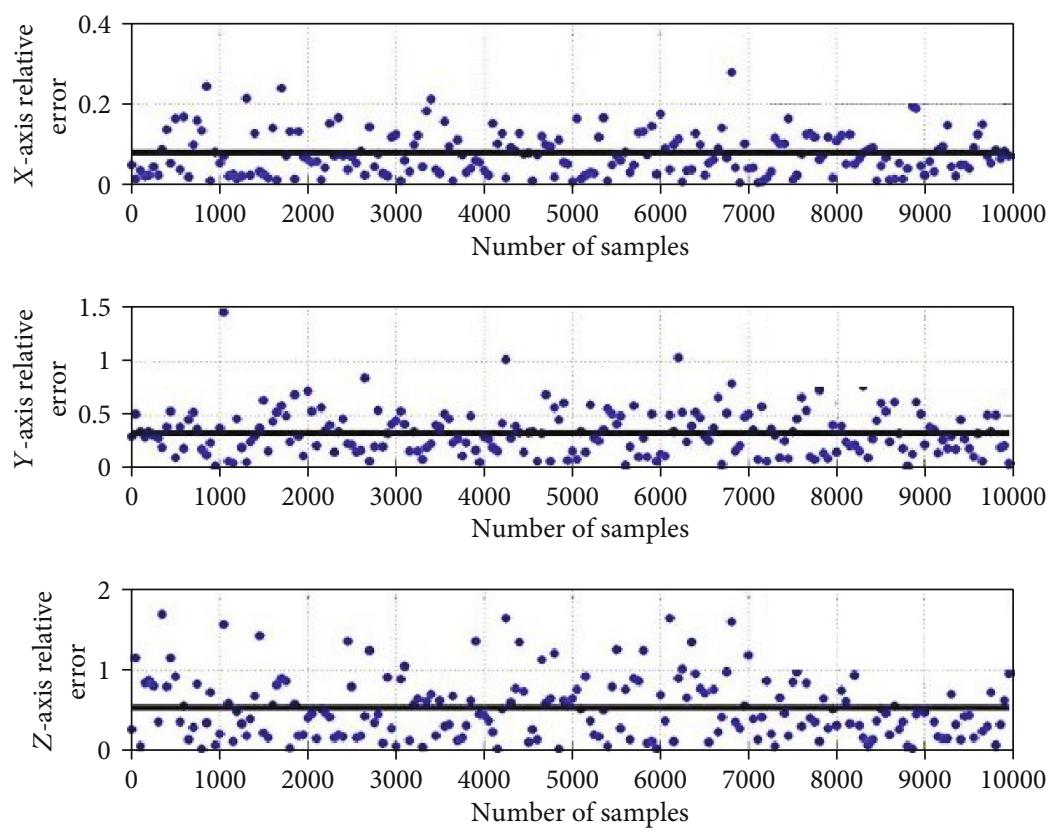

- Relative error

- Mean value

FIgURE 9: The simulation chart for the 4-3 layout method of excavation location P2, when $r=2 \mathrm{~m}$.

study was short. Assume that the spacing of the seismic detectors are $r=1.5 \mathrm{~m}$ and $r=2 \mathrm{~m}$, respectively, and the coordinates of excavation position are $\mathrm{P} 1(2.5,1,-0.7)$ and P2 $(2.5,-1,-0.7)$, respectively. Each seismic detector was introduced a uniformly distributed random delay error of $0.1 \mathrm{~ms} \sim 0.1 \mathrm{~ms}$ and a uniformly distributed random position of the error $-0.2 \mathrm{~m} \sim 0.2 \mathrm{~m}$. Assuming that $e=1 \mathrm{~m}, f=0.7$ $\mathrm{m}, g=2 \mathrm{~m}, h=1.7 \mathrm{~m}$, we use 10,000 samples for the simulation test (to facilitate observation, only 100 sampling points are displayed in the simulation chart). Figures 4-7 show the simulation results.

4.1.2. The Simulation of the 4-3 Layout Method. Model 4-3 has the same assumptions as model 5-1-1. Assuming that 

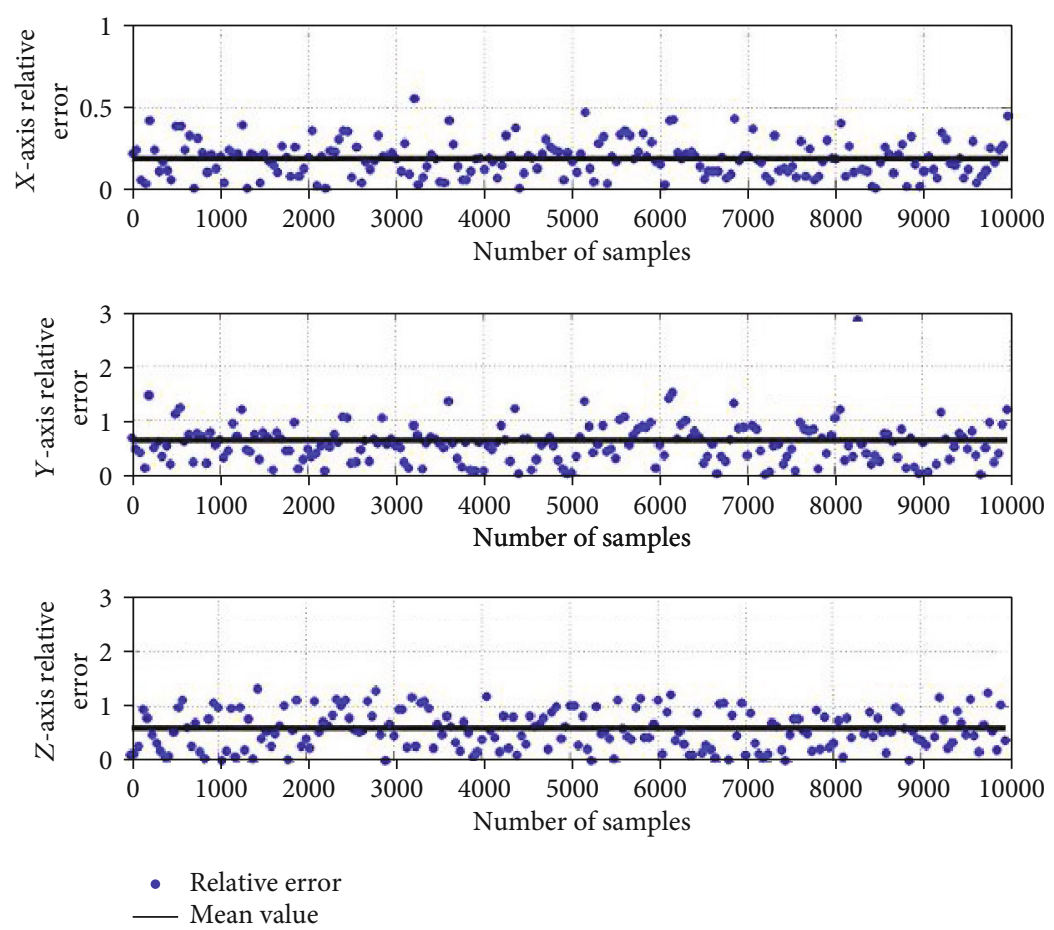

FIgURE 10: The simulation chart for the 4-3 layout method of excavation location P1, when $r=1.5 \mathrm{~m}$.
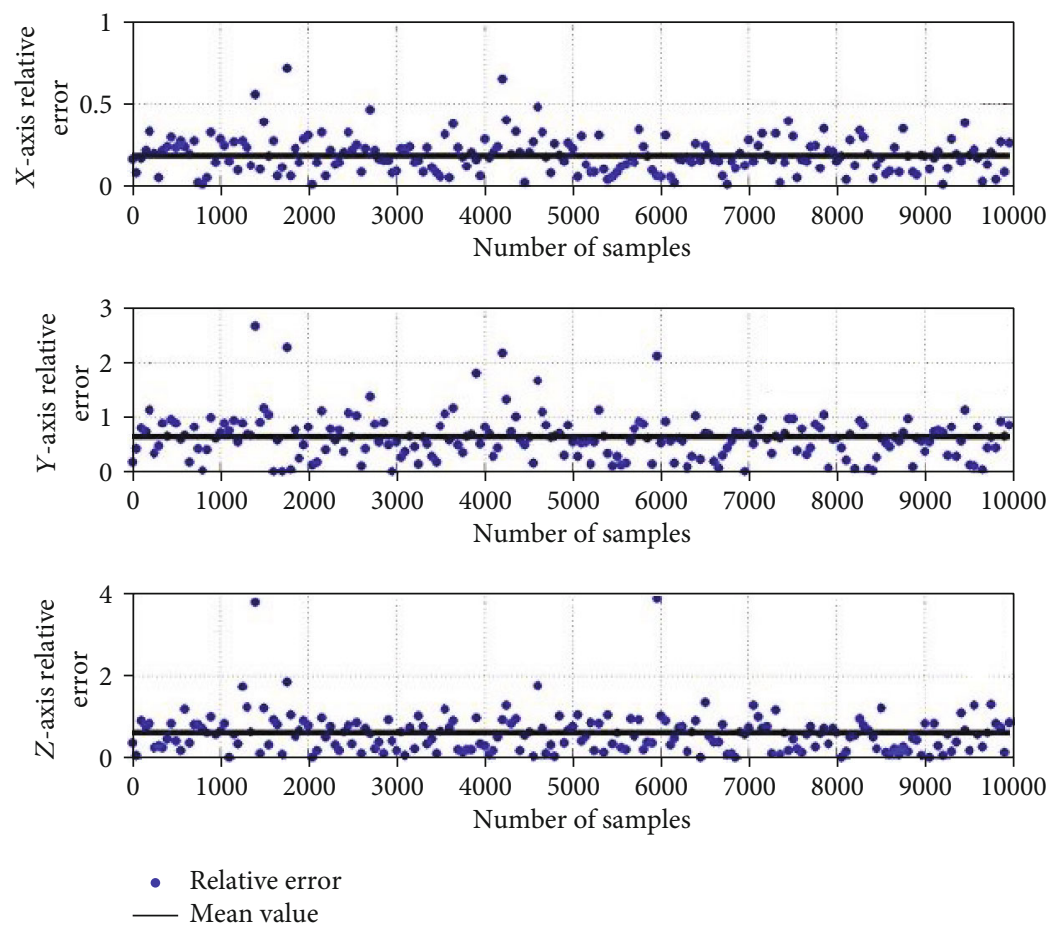

Figure 11: The simulation chart for the 4-3 layout method of excavation location P2, when $r=1.5 \mathrm{~m}$.

$i=3.4 \mathrm{~m}, j=1.1 \mathrm{~m}, k=1.7 \mathrm{~m}, u=2 \mathrm{~m}$, we use 10,000 samples for the simulation test. Figures $8-11$ show the simulation results.

4.1.3. The Simulation of the 7-0-0 Layout Method. Model 7-00 has the same assumptions as model 5-1-1. We use 10,000 samples for simulation tests. Figures $12-15$ show the simulation results.

4.2. The Analysis of Simulation Results. To simplify the use of A-X in Tables 2-5 instead of the average of the relative errors of the $X$-axis locating and U-L-X instead of the upper and 

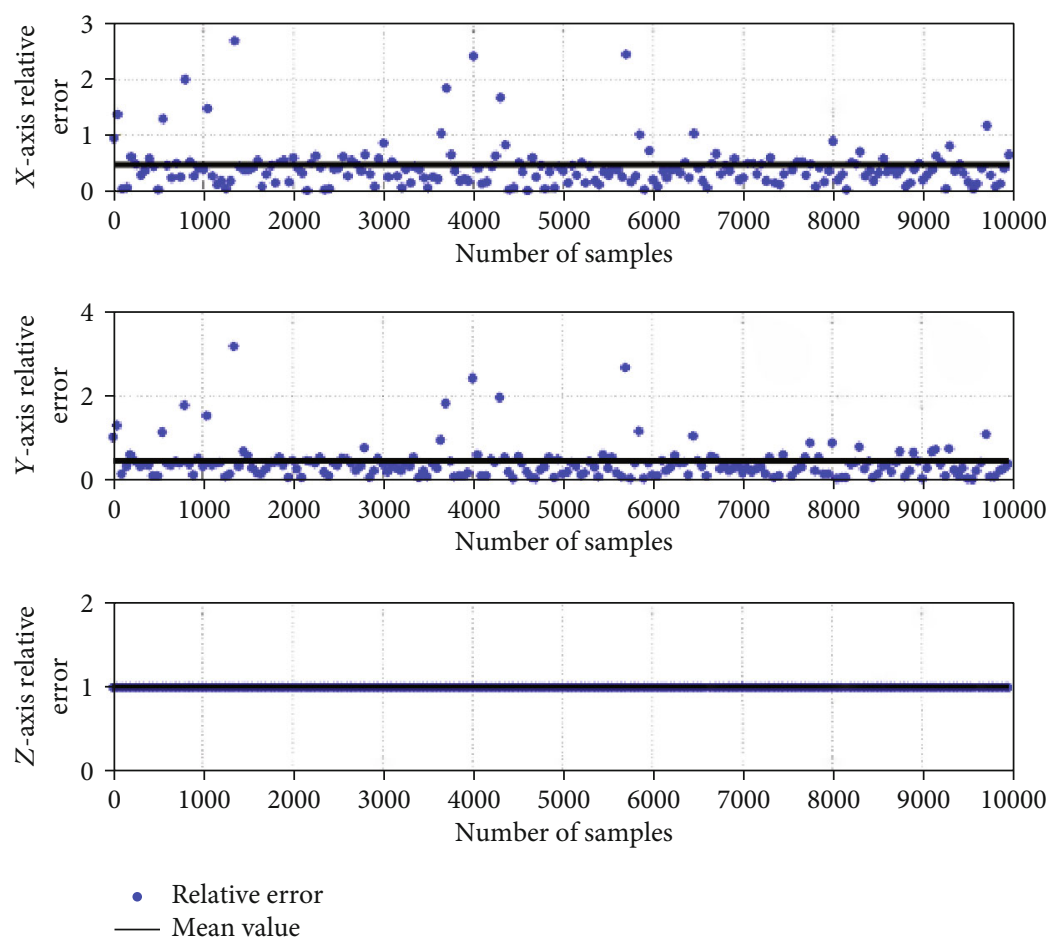

FIGURE 12: The simulation chart for the 7-0-0 layout method of excavation location P1, when $r=2 \mathrm{~m}$.
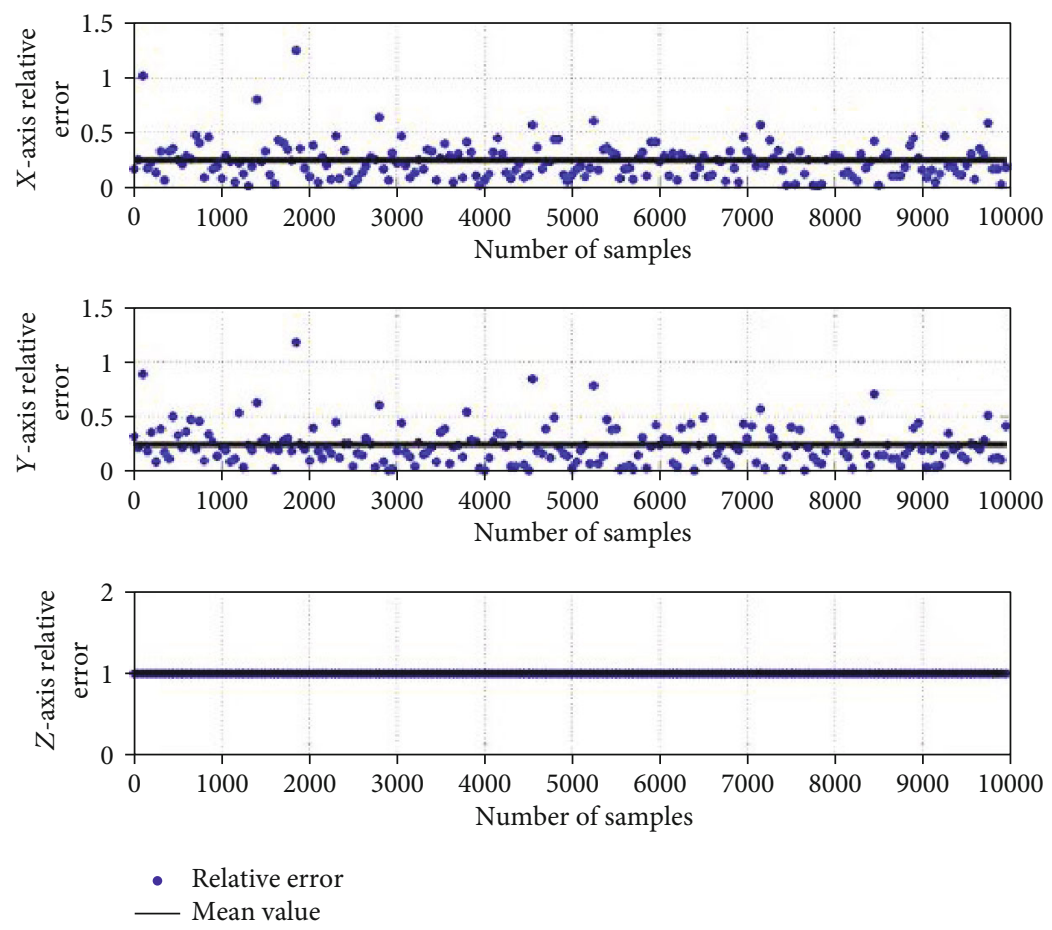

FIgURE 13: The simulation chart for the 7-0-0 layout method of excavation location P2, when $r=2 \mathrm{~m}$.

lower limits of the relative error of the $X$-axis locating, the $Y$ -axis and $Z$-axis are similar.

The simulation data from Tables $2-5$ shows the following:

(1) In-depth, the average value of the relative error of the $Z$-axis locating of the 5-1-1 layout method is greater than 2 meters, and the range of locatingrelated errors reaches $0-46.6$ meters at the maximum. The average value of the $Z$-axis locating relative error of the 4-3 layout method is about 0.8 meters. The range of related errors has reached $0-4.6$ meters, and the practical value is limited. The 

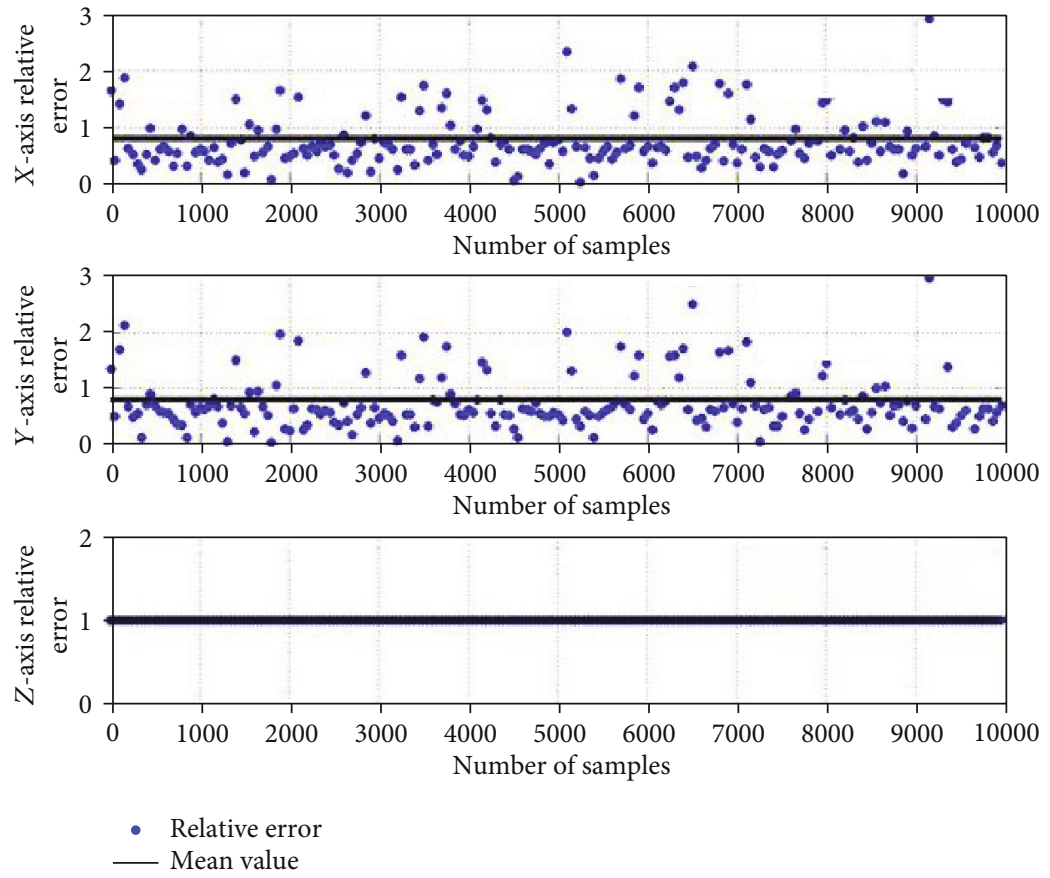

FIgURE 14: The simulation chart for the 7-0-0 layout method of excavation location P1, when $r=1.5 \mathrm{~m}$.
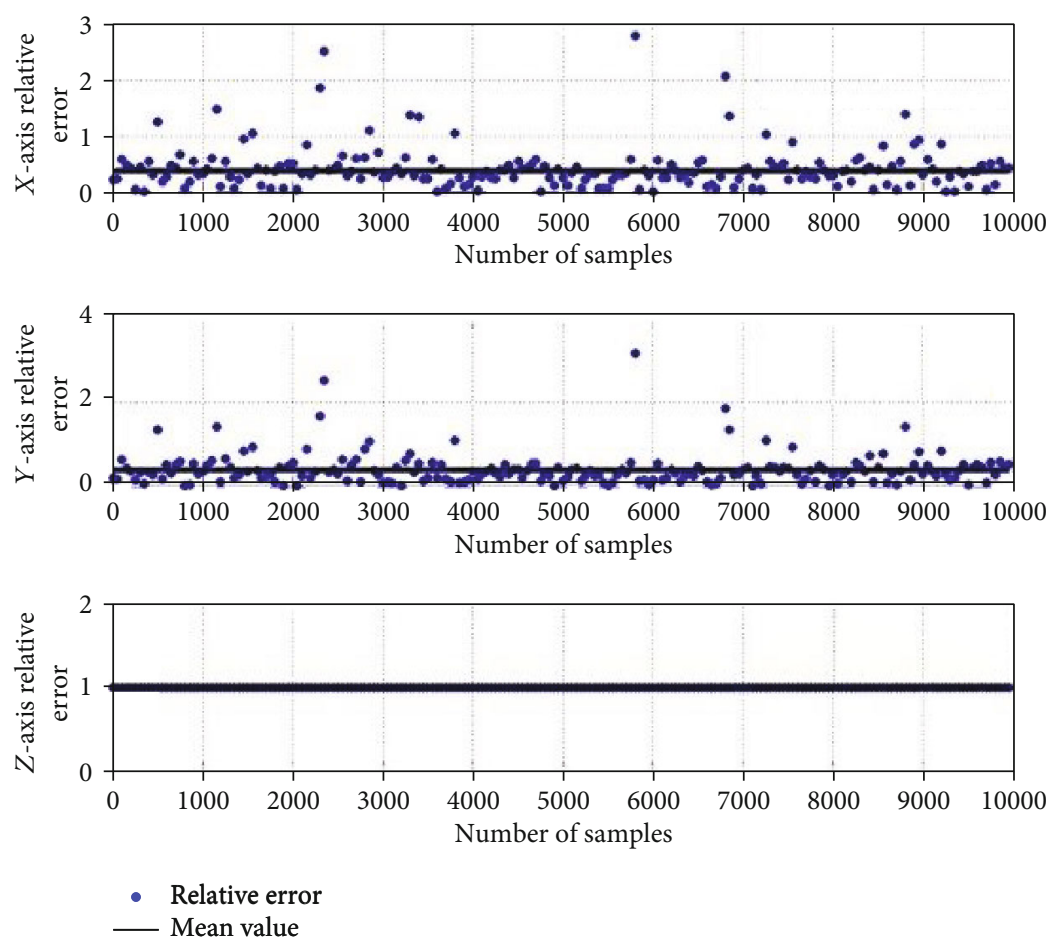

Figure 15: The simulation chart for the 7-0-0 layout method of excavation location P2, when $r=1.5 \mathrm{~m}$.

7-0-0 layout method does not have spatial locating capability

(2) The relative locating error is larger when the installation distance between the seismic detectors is 1.5 meters rather than the distance being 2 meters. It shows that the farther the distance between the seismic sensors is installed, the smaller the relative error of locating

(3) In the plane locating, the 7-0-0 layout method has no obvious advantage that the relative locating error is 
TABLE 2: Summary of simulation results of the coordinate of excavation location P1 when $r=2 \mathrm{~m}$.

\begin{tabular}{lcccccc}
\hline Method & A-X $(\mathrm{m})$ & U-L-X $(\mathrm{m})$ & A-Y $(\mathrm{m})$ & U-L-Y $(\mathrm{m})$ & A-Z $(\mathrm{m})$ & U-L-Z $(\mathrm{m})$ \\
\hline $5-1-1$ & 0.4 & $0-13.2$ & 0.4 & $0-11.7$ & 0.4 & $0-10.2$ \\
$4-3$ & 0.1 & $0-0.4$ & 0.3 & $0-3.8$ & 0.5 & $0-5.3$ \\
$7-0-0$ & 0.5 & $0-9.8$ & 0.5 & $0-9.3$ & 1 \\
\hline
\end{tabular}

TABLE 3: Summary of simulation results of the coordinate of excavation location P2 when $r=2 \mathrm{~m}$.

\begin{tabular}{|c|c|c|c|c|c|c|}
\hline Method & $\mathrm{A}-\mathrm{X}(\mathrm{m})$ & U-L-X (m) & A-Y (m) & U-L-Y (m) & $\mathrm{A}-\mathrm{Z}(\mathrm{m})$ & U-L-Z (m) \\
\hline $5-1-1$ & 0.7 & $0-12.3$ & 0.7 & $0-13$ & 0.5 & $0-18$ \\
\hline $4-3$ & 0.2 & $0-3$ & 0.6 & $0-15.6$ & 0.6 & $0-9.2$ \\
\hline $7-0-0$ & 0.8 & $0-12.3$ & 0.8 & $0-9.3$ & 1 & 1 \\
\hline
\end{tabular}

TABLE 4: Summary of simulation results of the coordinate of excavation location P1 when $r=1.5 \mathrm{~m}$.

\begin{tabular}{lcccccc}
\hline Method & A-X $(\mathrm{m})$ & U-L-X $(\mathrm{m})$ & A-Y $(\mathrm{m})$ & U-L-Y $(\mathrm{m})$ & A-Z $(\mathrm{m})$ & U-L-Z $(\mathrm{m})$ \\
\hline $5-1-1$ & 0.4 & $0-12.5$ & 0.4 & $0-11.7$ & 0.4 & $0-13$ \\
$4-3$ & 0.1 & $0-0.4$ & 0.3 & $0-2.9$ & 0.5 & $0-3.8$ \\
$7-0-0$ & 0.2 & $0-2.7$ & 0.2 & $0-2.9$ & 1 \\
\hline
\end{tabular}

TABLE 5: Summary of simulation results of the coordinate of excavation location P2 when $r=1.5 \mathrm{~m}$.

\begin{tabular}{lcccccc}
\hline Method & A-X $(m)$ & U-L-X $(m)$ & A-Y $(m)$ & U-L-Y $(m)$ & A-Z $(m)$ & 0.5 \\
\hline $5-1-1$ & 0.7 & $0-11.4$ & 0.7 & $0-14.1$ & $0-1-Z(m)$ \\
$4-3$ & 0.2 & $0-2.9$ & 0.6 & $0-9.4$ & 0.6 & $0-14.7$ \\
$7-0-0$ & 0.4 & $0-6.9$ & 0.4 & $0-6.9$ & 1 & 1 \\
\hline
\end{tabular}

small compared with the 5-1-1 layout method and 4-3 layout method. It is not that the more the seismic detector is placed on the plane, the higher the accuracy

4.3. Experimental Verification. To further illustrate the issue, this paper had carried out an experimental verification. The experimental hardware is described in Ref. 24. Seven seismic detectors were used. When the propagation velocity of the seismic wave was tested, seven seismic detectors were lined up and people hit the ground. Figure 16 shows the experimental field of measuring the propagation velocity of the seismic wave. Figure 17 shows the information on the seismic wave acquired by the experiment. Figure 18 shows a selected set of seismic wave propagation information.

As can be seen from Figure 18, the coordinates in Figure 18 indicated the sampling point number and voltage values when the seven seismic sensors received the first wave of the seismic signal. The velocity of the seismic wave is obtained by the distance between the known seven seismic detectors, the interval time, and the difference in sampling points. The measurement results of seismic wave velocity are shown in Table 6. Through experimental tests, the propagation velocity of the seismic wave is about $380 \mathrm{~m} / \mathrm{s}$ in this geological condition.

Due to the monitoring, the area is smaller and the distance between seismic detectors is relatively close. Limited by the cost control of underground excavation systems, the frequency of the seismic detector is not high. The seismic detector performance is also difficult to distinguish between $P$-wave, $S$-wave, and Rayleigh waves. The seismic detector used in this paper also does not use the gain adaptive technology, and the signal has the top-cutting phenomenon. In the study, the center of the top-cutting signal is selected as the point where the maximum signal is located. In the later stage, if more research funds are obtained, it can be verified with better-performing seismic detectors (after adopting adaptive gain technology, the consistency requirement of each seismic detector is higher).

On this basis, this paper also carried out the locating experiment of the 5-1-1 layout method, 4-3 layout method, and 7-0-0 layout method. The seismic detector was arranged according to the space coordinates of the previous simulation. Two spacings were used during the experiment: one was 1.5 meters and the other was 2 meters. There are two excavation positions: $\mathrm{P} 1(2.5,1,-0.7)$ and $\mathrm{P} 2(2.5,-1,-0.7)$. Figure 19 is a photo of the locating experiment site. Figure 20 shows a set of data of the 5-1-1 layout method locating experiment when $r=2 \mathrm{~m}$ and the coordinates of the excavation position are $\mathrm{P} 1(2.5,1,-0.7)$, and Figure 21 is a partially enlarged view of it. Figure 22 shows a set of data of the 5-1-1 layout method locating experiment when $r=2$ $\mathrm{m}$ and the coordinates of the excavation position are 


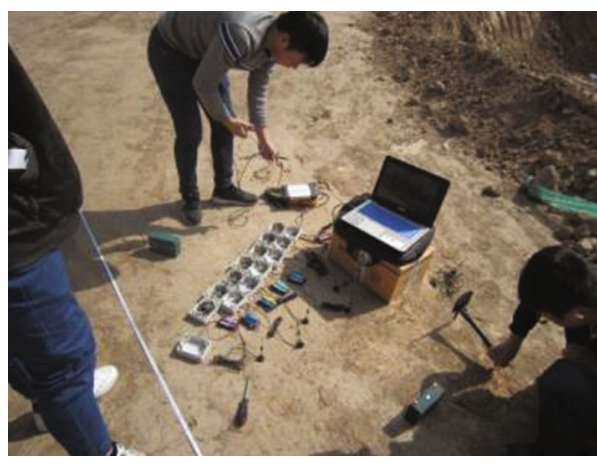

(a)

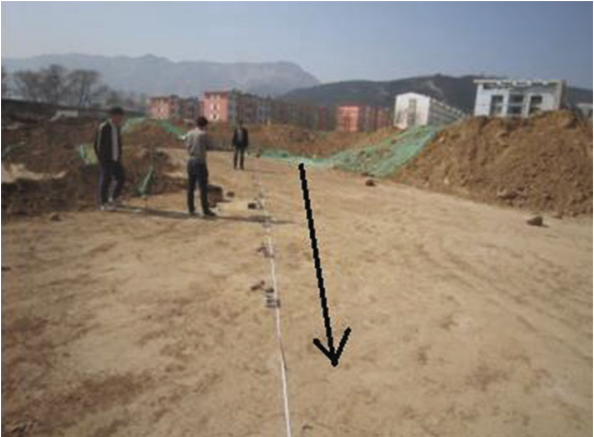

(b)

Figure 16: The measurement experiment of seismic wave propagation velocity.

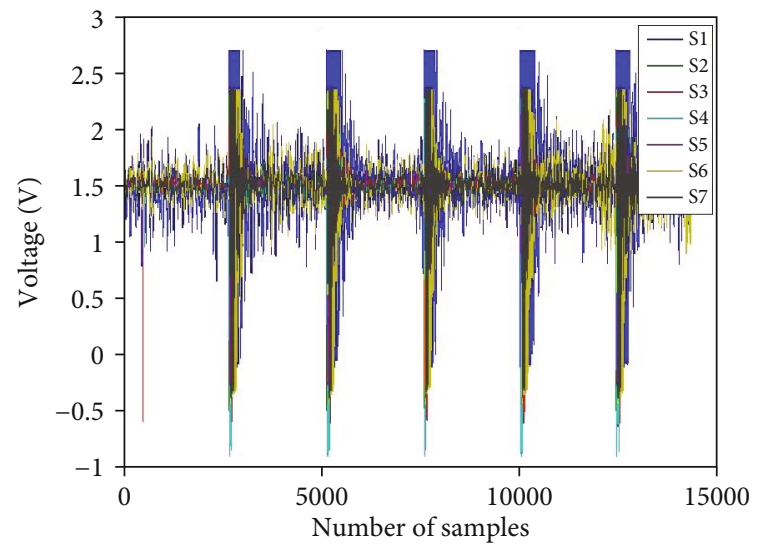

FIGURE 17: The information on the seismic waves acquired by the experiment.

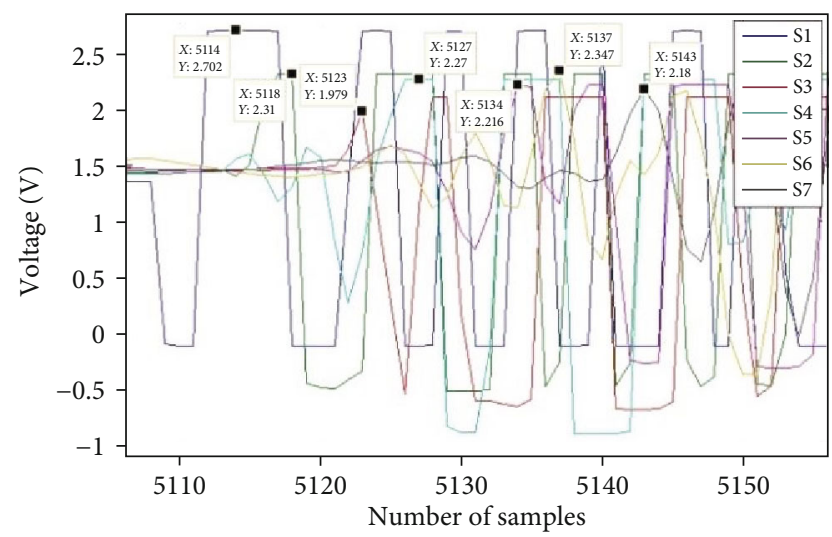

FIGURE 18: A selected set of seismic wave propagation information.

P2 $(2.5,-1,-0.7)$, and Figure 23 is a partially enlarged view of it. Tables 7-10 are experimental data statistics.

\subsection{Result Analysis}

(1) In terms of depth locating, relative errors are relatively large
TABLE 6: The measurement values of the seismic detectors.

\begin{tabular}{lc}
\hline $\begin{array}{c}\text { Number } \\
\text { The estimated propagation velocity } \\
\text { for seismic wave }(\mathrm{m} / \mathrm{s})\end{array}$ \\
\hline 1 & 344 \\
2 & 382 \\
3 & 396 \\
4 & 404 \\
5 & 374 \\
6 & 356 \\
7 & 371 \\
8 & 387 \\
9 & 397 \\
10 & 389 \\
Average value & 380 \\
\hline
\end{tabular}

The 5-1-1 layout method showed a relative error of 8.9 meters on the $Z$-axis locating. The 4-3 layout method showed a relative locating error of 7 meters on the $Z$-axis, which was much larger than the layout distance of the seismic detector. At the same time, the simulation results also show that the relative locating error of the 5-1-1 layout method and the 4-3 layout method in the $Z$-axis has a large spread, indicating that the $Z$-axis locating results of the 5-1-1 layout method and the 4-3 layout method do not have value for engineering. The 7-0-0 layout method does not have depth locating capability.

(2) Increasing the installation distance between seismic detectors can reduce relative locating errors

The relative locating error is smaller when the installation distance between the seismic detectors is 2 meters rather than the installation distance being 1.5 meters in the same layout method and the same excavation location. This conclusion is by simulation results, which shows that increasing the installation distance between seismic detectors can reduce relative locating errors.

(3) The relative locating error does not depend on how many the seismic detector is arranged 


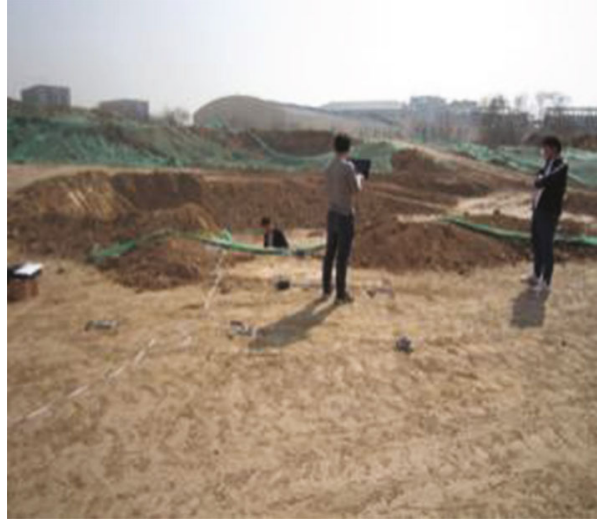

(a)

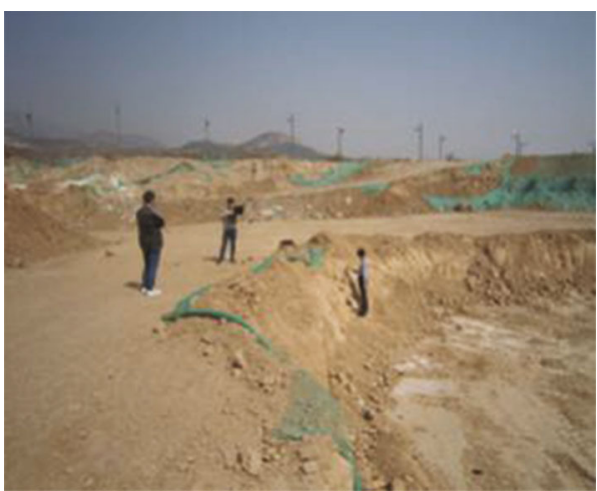

(b)

Figure 19: The locating experiment.

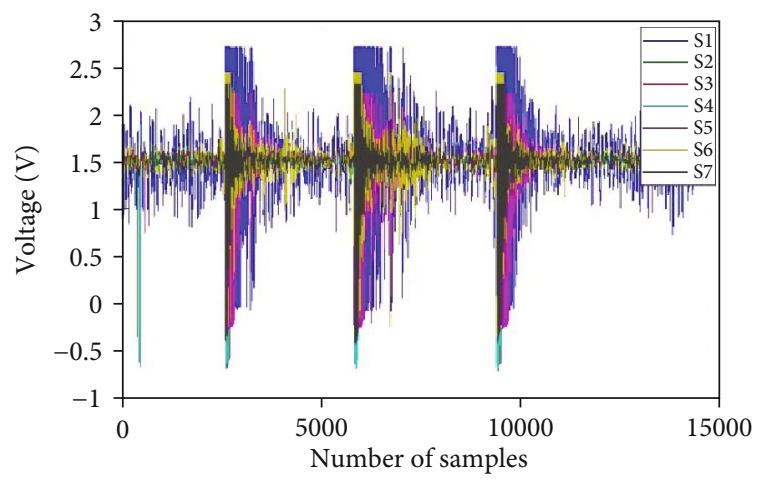

Figure 20: A set of data of the 5-1-1 layout method locating experiment when $r=2 \mathrm{~m}$. The coordinates of the excavation position are P1.

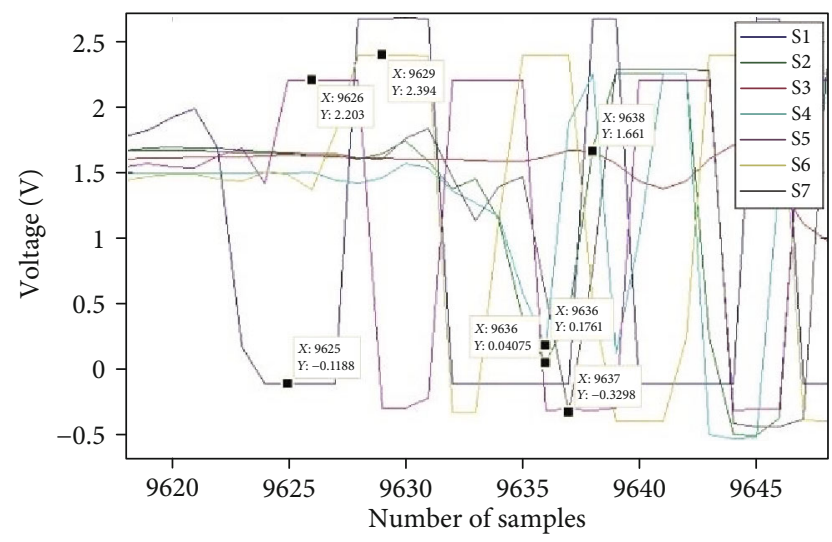

Figure 21: A partially enlarged view of Figure 20.

The 5-1-1 layout method deploys five seismic detectors in the plane consisting of the $X$-axis and $Y$-axis, the 4-3 layout method deploys four seismic detectors, and the 7-0-0 layout method deploys seven detectors. However, neither the experimental results nor the simulation results support the traditional understanding that the more the seismic detectors are arranged on the plane, the higher the accuracy. The main

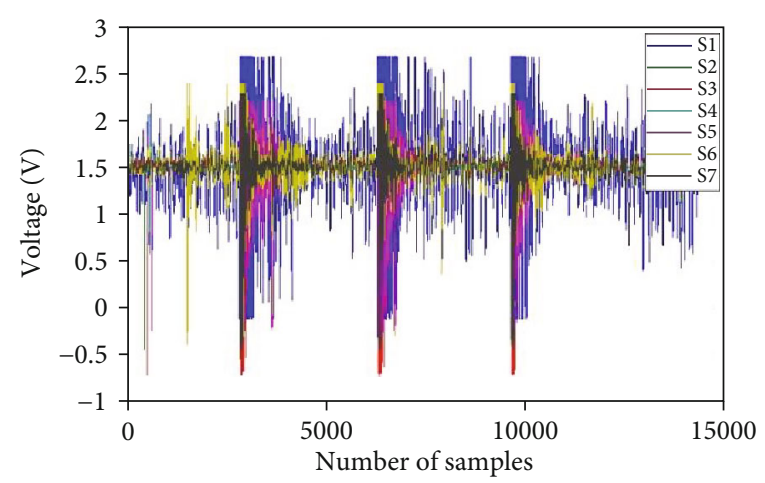

FIgURe 22: A set of data of the 5-1-1 method locating experiment when $r=2 \mathrm{~m}$. The coordinates of the excavation position are $\mathrm{P} 2$.

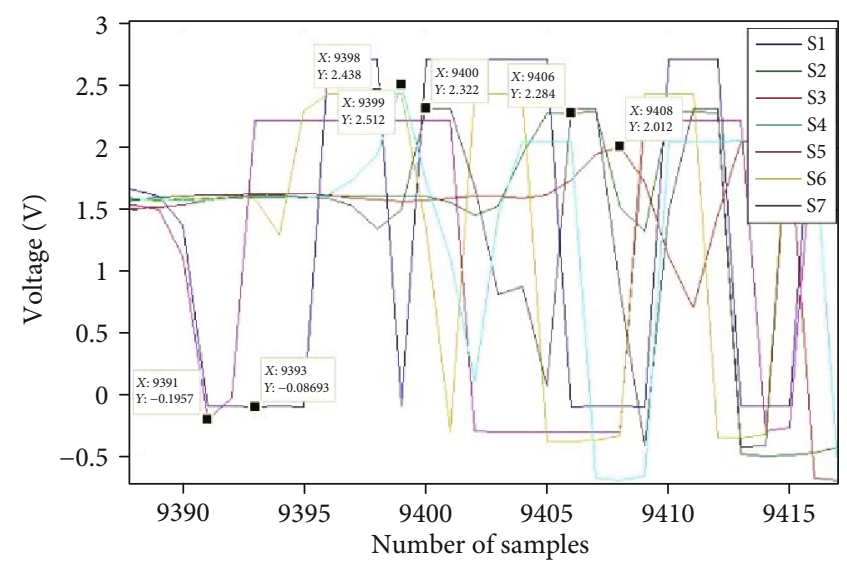

FIgURE 23: A partially enlarged view of Figure 22.

reason is the time measurement error, the difference in transmission velocity caused by the terrain, and the detection performance of the seismic detector hardware itself.

(4) Due to geological differences, relative locating errors are also different for the same layout method when the excavation position is different 
TABLE 7: Summary of experimental results of the coordinate of excavation location P1 $(2.5,1,-0.7)$ when $r=2 \mathrm{~m}$.

\begin{tabular}{cccc}
\hline & $\begin{array}{c}\text { The locating } \\
\text { relative error of } \\
\text { the } X \text {-axis }(\mathrm{m})\end{array}$ & $\begin{array}{c}\text { The locating } \\
\text { relative error of } \\
\text { the } Y \text {-axis }(\mathrm{m})\end{array}$ & $\begin{array}{c}\text { The locating } \\
\text { relative error of } \\
\text { the } Z \text {-axis }(\mathrm{m})\end{array}$ \\
\hline \multirow{4}{*}{$5-1-1$} & 0.04 & 0.23 & 0.15 \\
& 0.41 & 1.04 & 1.2 \\
$4-3$ & 0.09 & 0.56 & 0.35 \\
& 0.05 & 0.15 & 3.1 \\
& 0.05 & 0.62 & 1.79 \\
$7-0-0$ & 0.01 & 0.01 & 3.24 \\
& 0.44 & 0.48 & - \\
& 0.54 & 0.19 & - \\
\hline
\end{tabular}

TABLE 8: Summary of experimental results of the coordinate of excavation location P2 $(2.5,-1,-0.7)$ when $r=2 \mathrm{~m}$.

\begin{tabular}{cccc}
\hline & $\begin{array}{c}\text { The locating } \\
\text { relative error of } \\
\text { the } X \text {-axis }(\mathrm{m})\end{array}$ & $\begin{array}{c}\text { The locating } \\
\text { relative error of } \\
\text { the } Y \text {-axis }(\mathrm{m})\end{array}$ & $\begin{array}{c}\text { The locating } \\
\text { relative error of } \\
\text { the } Z \text {-axis }(\mathrm{m})\end{array}$ \\
\hline \multirow{4}{*}{$5-1-1$} & 0.57 & 1.36 & 4.14 \\
& 0.95 & 0.91 & 6.63 \\
$4-3$ & 1.28 & 0.97 & 8.9 \\
& 0.04 & 1.03 & 1.07 \\
& 0.21 & 0.62 & 0.02 \\
$7-0-0$ & 0.64 & 0.51 & 6.41 \\
& 0.87 & 1.16 & - \\
& 0.54 & 0.56 & - \\
\hline
\end{tabular}

TABLE 9: Summary of experimental results of the coordinate of excavation location P1 $(2.5,1,-0.7)$ when $r=1.5 \mathrm{~m}$.

\begin{tabular}{cccc}
\hline & $\begin{array}{c}\text { The locating } \\
\text { relative error of } \\
\text { the } X \text {-axis }(\mathrm{m})\end{array}$ & $\begin{array}{c}\text { The locating } \\
\text { relative error of } \\
\text { the } Y \text {-axis }(\mathrm{m})\end{array}$ & $\begin{array}{c}\text { The locating } \\
\text { relative error of } \\
\text { the } Z \text {-axis }(\mathrm{m})\end{array}$ \\
\hline \multirow{4}{*}{$5-1-1$} & 0.52 & 1.4 & 2.5 \\
& 1.32 & 4.05 & 6.8 \\
& 1.32 & 4.1 & 6.72 \\
$4-3$ & 0.29 & 1 & 2.4 \\
& 0.11 & 0.95 & 0.64 \\
$7-0-0$ & 0.6 & 0.79 & 3.4 \\
& 0.52 & 0.08 & - \\
& 0.75 & 0.54 & - \\
\hline
\end{tabular}

In the theoretical simulation, the hypothesis is based on the same geological conditions, but in the actual experiment, the geological conditions are unlikely to be consistent. Therefore, the relative errors in locating are different when two different excavation locations P1 and P2 are excavated.
TABLE 10: Summary of experimental results of the coordinate of excavation location P2 $(2.5,-1,-0.7)$ when $r=1.5 \mathrm{~m}$.

\begin{tabular}{cccc}
\hline & $\begin{array}{c}\text { The locating } \\
\text { relative error of } \\
\text { the } X \text {-axis }(\mathrm{m})\end{array}$ & $\begin{array}{c}\text { The locating } \\
\text { relative error of } \\
\text { the } Y \text {-axis }(\mathrm{m})\end{array}$ & $\begin{array}{c}\text { The locating } \\
\text { relative error of } \\
\text { the } Z \text {-axis }(\mathrm{m})\end{array}$ \\
\hline $5-1-1$ & 0.6 & 0.6 & 1.6 \\
& 0.9 & 1.1 & 4 \\
$4-3$ & 0.3 & 0.5 & 0.2 \\
& 0.92 & 0.95 & 5.7 \\
& 0.5 & 1.1 & 0.5 \\
$7-0-0$ & 1 & 0.64 & - \\
& 0.08 & 0.88 & - \\
\hline
\end{tabular}

Therefore, locating methods of underground excavation need to expand research.

\section{Conclusion}

The paper focuses on the locating of underground excavation monitoring systems. Through mathematical modeling, simulation, and experiments, the following conclusions are obtained. (1) When the number of seismic detectors is limited, the depth positioning error is relatively large. (2) To increase the installation distance between the vibration detectors around the place, the relative error of plane positioning can be reduced. (3) The main reasons for the positioning error are the time measurement error, the difference in transmission velocity caused by the terrain, and the detection performance of the seismic detector hardware itself. At close range, the influence of the seismic detector's layout method on the positioning error is limited. The above research results can help the application of an underground excavation system.

\section{Data Availability}

The data used to support the findings of this study are available from the corresponding author upon request.

\section{Conflicts of Interest}

The authors declare no conflict of interest.

\section{Acknowledgments}

This work was supported by the Focus on Research and Development Program (general) in Shanxi under grant 201603 D121038.

\section{References}

[1] T. Yue and C. Xiaofei, "Review of seismic location study," Progress in Geophysics, vol. 17, no. 1, pp. 147-155, 2002. 
[2] L. Geiger, "Probability method for the determination of earthquake epicenters from arrival time only," Bull. St. Louis. Univ, vol. 8, no. 60, p. 71, 1912.

[3] B. R. Lienert, E. Berg, and L. N. Frazer, "Hypocenter: an earthquake location method using centered, scaled, and adaptively damped least squares," Bulletin of the Seismological Society of America, vol. 76, no. 3, pp. 771-783, 1986.

[4] G. D. Nelson and J. E. Vidale, "Earthquake locations by 3D finite difference travel times," Bulletin of the Seismological Society of America, vol. 80, no. 2, pp. 395-410, 1990.

[5] Z. Zhonghe, "An earthquake location program with multiple velocity model and its application to the Beijing seismic network," Acta Seismologica Sinica, vol. 5, no. 2, pp. 242-254, 1983.

[6] A. F. Prugger and D. J. Gendzwill, "Microearthquake location: a nonlinear approach that makes use of a simplex stepping procedure," Bulletin of the Seismological Society of America, vol. 78, no. 2, pp. 799-815, 1988.

[7] R. S. Crosson, "Crustal structure modeling of earthquake data: 1. Simultaneous least squares estimation of hypocenter and velocity parameters," Journal of Geophysical Research, vol. 81, no. 17, pp. 3036-3046, 1976.

[8] K. Aki and W. H. K. Lee, "Determination of three-dimensional velocity anomalies under a seismic array using first $\mathrm{P}$ arrival times from local earthquakes: 1. A homogeneous initial model," Journal of Geophysical Research, vol. 81, no. 23, pp. 4381-4399, 1976.

[9] G. Pavlis and J. R. Booker, "The mixed discrete-continuous inverse problem: application to the simultaneous determination of earthquake hypocenters and velocity structure," Journal of Geophysical Research, vol. 85, no. B9, pp. 4801-4810, 1980.

[10] Z. Zhonghe, "The joint determination of hypocenter parameters and velocity structure in the Beijing area of China," Chinese Journal of Geophysics, vol. 26, no. 2, pp. 131-139, 1983.

[11] L. Futian, "Simultaneous inversion of earthquake hypocenters and velocity structure (I): theory and method," Chinese Journal of Geophysics, vol. 27, no. 2, pp. 167-175, 1984.

[12] G. Fuan and F. Rui, "The joint inversion of $3 \mathrm{D}$ velocity structure and source parameters in Xinfengjiang reservoir," Chinese Journal of Geophysics, vol. 35, no. 3, pp. 331-341, 1992.

[13] H. S. Ma, G. M. Zhang, L. Q. Zhou, J. Liu, and H. Xia, "Simultaneous inversion of small earthquake relocation and velocity structure in Sichuan-Yunnan area," Earth, vol. 28, no. 2, p. 29-8, 2008.

[14] Z. Ren, L. Wang, and L. Bi, "Robust GICP-based 3D LIDAR SLAM for underground mining environment," Sensors, vol. 19, no. 13, p. 2915, 2019.

[15] W. Feng, S. Lei, F. Weiguo, and W. Cong, "Application of computational geometry in coal mine roadway $3 \mathrm{D}$ localization," The International Arab Journal of Information Technology, vol. 15, no. 4, 2018.

[16] H. Chen, W. Guan, S. Li, and Y. Wu, "Indoor high precision three-dimensional positioning system based on visible light communication using modified genetic algorithm," Optics Communications, vol. 413, no. 15, pp. 103-120, 2018.

[17] H. Huang, B. Lin, L. Feng, and H. Lv, "Hybrid indoor localization scheme with image sensor-based visible light positioning and pedestrian dead reckoning," Applied Optics, vol. 58, no. 12, pp. 3214-3221, 2019.
[18] L. Zhe, The Key Technology of Underground Seismic Signal Detection and Recognition in the Area of Public Security, China University of Mining and Technology, Beijing, 2015.

[19] W. Tao, W. Dongying, P. Yu, and F. Wei, "Gas leak localization and detection method based on a multi-point ultrasonic sensor array with TDOA algorithm," Measurement Science and Technology, vol. 26, no. 9, article 095002, 2015.

[20] S.-Y. Jung, S. Hann, and C.-S. Park, "TDOA-based optical wireless indoor localization using LED ceiling lamps," IEEE Transactions on Consumer Electronics, vol. 57, no. 4, pp. 1592-1597, 2011.

[21] J. Shen, A. F. Molisch, and J. Salmi, “Accurate passive location estimation using TOA measurements," IEEE Transactions on Wireless Communications, vol. 11, no. 6, pp. 2182-2192, 2012.

[22] K. C. Ho, "Bias reduction for an explicit solution of source localization using TDOA," IEEE Transactions on Signal Processing, vol. 60, no. 5, pp. 2101-2114, 2012.

[23] J. L. Wang, D. Z. Qin, S. Y. Pei, and T. L. Zhao, "Design of seismic signal detection and identification system based on STM32," Foreign Electronic Measurement Technology, vol. 36, no. 7, pp. 48-51, 2017.

[24] D. Qin and J. Zhang, "A new identification method of underground excavation based on velocity estimation using double point synchronous measurements," IEEE Access, vol. 8, pp. 39104-39112, 2020. 